\title{
PROTOTYPE KUNCI RFID (RADIO FREQUENCY IDENTIFICATION) DALAM MENINGKATKAN KEAMANAN KENDARAAN BERMOTOR
}

\author{
Imam Muslem R ${ }^{1)}$ \\ ${ }^{1)}$ Program Studi Informatika, Fakultas Ilmu Komputer, Universitas Almuslim Bireuen \\ e-mail:imamtkj@gmail.com
}

\begin{abstract}
[Prototype of RFID (Radio Frequency Identification) Key in Improving Motor Vehicle Safety] This research was conducted to develop a motorized vehicle locking system as an effort to improve motor vehicle safety from theft and loss. The problem-solving concept used is by using the RFID system which works by means of communication between RFID tags using the e-KTP card as an opening key and the RFID reader as a key reader. The system development method used is the prototype development method wherein this method the system will continue to be developed by repeating the design and implementation to suit user needs. As long as the system required by the user has not been fulfilled optimally, the development will continue to be carried out. The results obtained are that the system has been successfully implemented with a working concept, namely the e-KTP card is brought closer to the RFID reader installed on a motorized vehicle, then the unique code on the e-KTP is read by the RFID reader which works at a frequency of 13.56 $\mathrm{MHz}$, then the id sent to the microcontroller as a processing device in this system to be verified as a valid id card which will then instruct the actuator, namely the relay device to activate the overall electrical system so that the vehicle can be turned on and run. This study also tested the distance and material that obstructed the RFID tag and the RFID Reader which resulted in the conclusion that the effective distance of the e-KTP card read by the RFID reader is $3 \mathrm{~cm}$. Meanwhile, the material testing for 10 barrier materials was only 5 materials that did not obstruct the reading of the RFID tag by the RFID reader, namely 1 sheet of HVS paper, 50 sheets of HVS paper, plastic, $0.5 \mathrm{~cm}$ of acrylic, and 1 piece of cloth. Meanwhile, metal materials such as iron, zinc, and aluminum become a reading barrier between the RFID tag and the RFID Reader.
\end{abstract}

Keywords: e-KTP; Motor Vehicle Safety; Prototype; RFID.

\begin{abstract}
Abstrak
Penelitian ini dilakukan untuk mengembangkan suatu sistem penguncian kendaraan bermotor untuk sebagai upaya dalam meningkatkan keamanan kendaraan bermotor dari aksi pencurian dan kehilangan. Konsep penyelesaian masalah yang digunakan yaitu dengan menggunakan sistem RFID yang bekerja dengan cara komunikasi antara RFID taq menggunakan kartu e-KTP sebagai kunci pembuka serta RFID reader sebagai pembaca kunci. Metode pengembangan sistem yang digunakan yaitu metode pengembangan prototype dimana pada metode ini sistem akan terus dikembangkan dengan perulangan pada perancangan dan implemetasi agar sesuai dengan kebutuhan user. Selama sistem yang dibutuhkan oleh user belum terpenuhi secara maksimal maka akan terus dilakukan pengembangan. Hasil yang diapat yaitu sistem berhasil diimplementasi dengan konsep kerja yaitu kartu e-KTP didekatkan dengan RFID reader yang dipasang pada kendaraan bermotor, kemudian kode unik yang ada pada e-KTP dibaca oleh RFID reader yang bekerja pada frekuensi 13,56 MHz, kemudian id tersebut dikirim ke mikrokontroler sebagai perangkat pemroses dalam sistem ini untuk diverifikasi sebagai id card sah yang nantinya akan memerintahkan aktuator yaitu perangkat relay untuk mengaktfkan sistem kelistrikan secara keseluruhan sehingga kendaraan dapat dihidupkan dan dijalankan. Dalam penelitian ini juga dilakukan pengujian jarak dan material yang menghalangi antara RFID tag dan RFID Reader yang menghasilkan kesimplan bahwa jarak efektif kartu e-KTP terbaca oleh RFID reader yaitu berjarak $3 \mathrm{~cm}$. Sedangkan pengujian material untuk 10 material penghalang hanya 5 material yang tidak menghalangi pembacaan RFID tag oleh RFID reader yaitu kertas HVS 1 lembar, kertas HVS 50
\end{abstract}


lembar, plastik, arklik setebal 0,5 cm serta kain 1 helai. Sedangkan untuk bahan material logam seperti besi, seng dan aluminium menjadi penghalang pembacaan antara RFID tag dan RFID Reader.

Kata Kunci: e-KTP; Keamanan Kendaraan Bermotor; Prototype; RFID.

\section{Pendahuluan}

Kendaraan bermotor yang masih menggunakan kunci konvensional berbentuk kunci fisik tidak sepenuhnya aman dari kasus pencurian dan kehilangan. Di Indonesia sendiri umumnya kendaraan bermotor mayoritas menggunakan sistem keamanan berbentuk kunci fisik yang sangat rentan terhadap pembobolan dan pencurian. Cara kerja kunci fisik tersebut yaitu kunci yang terbuat dari bahan logam digunakan dengan cara dimasukkan kedalam lubang kunci yang ada pada kendaraan bermotor, lalu diputar ke arah tertentu dengan derajat tertentu sehingga posisi terkunci berubah menjadi tidak terkunci dan begitu juga sebaliknya. Sistem konvensional tentu memiliki celah keamanan pada bagian kunci dan lubang kuncinya. Kunci yang terbuat dari logam bisa dengan mudah diduplikasi dengan mencetak kunci baru dari logam dengan bentuk dan ukuran yang sama dengan kunci aslinya (Asmawati \& Sari, 2019). Disamping itu mekanisme lubang kunci konvensional yang ada pada kendaraan bermotor juga memiliki celah keamanan yang dirusak secara paksa sehingga kendaraan bermotor dapat dihidupkan tanpa harus menggunakan kunci aslinya (Priyadi, 2017). Dari informasi yang didapatkan bahwa di Indonesia sendiri banyak terjadi kasus pencurian dan kehilangan kendaraan bermotor yang dilakukan dengan cara merusak kunci dengan menggunakan kunci T (Artika, 2013).

Dalam mengatasi masalah tersebut, berbagai pabrikan otomotif berlomba-lomba untuk mengembangkan sistem penguncian kendaraan bermotor yang lebih efektif dan efisien. Misalnya teknologi yang dikembangkan oleh Honda salah satu pabrikan otomotif besar jepang yang menerapkan konsep keyless yaitu kunci pintar berbasis wireless yang digunakan cukup dengan mengantongi kuncinya saja. Sistem ini cukup aman dikarenakan kendaraan bermotor hanya akan hidup selama kunci berada pada jarak tertentu dengan kendaraan bermotor (Iwan, Rahayu, \& Yulianto, 2018). Sistem kelistrikan pada kendaraan bermotor akan otomatis terputus apabila mencapai jarak tertentu antara kendaraan dengan kunci keyless sehingga sistem seperti dapat dikatakan aman dikarenakan kendaraan bermotor tidak dapat dihidupkan apabila kunci keyless tidak berada dekat dengan motor tersebut (Risyad, 2018).

Dengan adanya inovasi dari teknologi keyless terbukti dapat meningkatkan keamanan kendaraan bermotor. Namun sistem keyless hanya ditemukan pada kendaraan bermotor terbaru dimana apabila diterapkan pada kendaraan bermotor keluaran lama tentu akan menghabiskan biaya yang besar. Oleh karena itu dalam penelitian ini akan dibahas mengenai pengembangan sistem penguncian untuk kendaraan bermotor yang mampu meningkatkan keamanan yang sama yang dimiliki oleh sistem keyless terbaru namun dengan biaya yang lebh murah apabila diterapkan pada kendaraan bermotor keluaran lama.

Adapun sistem yang dimaksudkan yaitu sistem yang dikembangkan dengan menggunakan perangkat sensor RFID (Radio Frequency Identification) sebagai receiver kunci serta e-KTP sebagai transmitter kunci (Astono, 2006; Chen, Reade, \& Lindsay, 2005; Grabau et al., 2002; Youssef, Bassim, \& Gabriel, 2011). Gambaran konsep kerjanya yaitu e-KTP digunakan untuk mengaktifkan sistem kelistrikan yang ada pada kendaraan bermotor dengan menempelkannya pada perangkat receiver RFID yang dipasang pada sepeda motor.

\section{Metode}

A. Metode Pengembangan Sistem

Adapun metode yang digunakan dalam penelitian ini yaitu metode pengembangan prototype (Purnomo, 2017). Pada metode ini sistem dikembangkan dengan menargetkan kebutuhan pengguna. Sistem akan terus dilakukan perbaikan dengan melihat ketercapaian dan keseuaian antara prototype dengan kebutuhan pengguna. Gambaran umum dari sistem prototype dapat dilihat pada gambar berikut ini: 


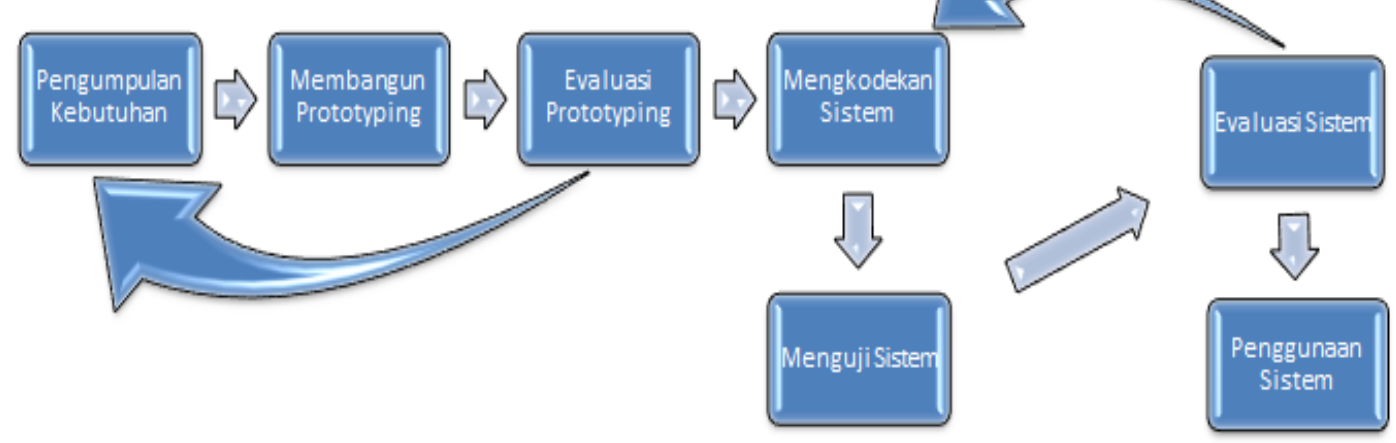

Gambar 1. Metode Prototype

\section{B. Konsep Kerja Sistem}

Sistem penguncian kendaraan bermotor yang dikembangkan dalam penelitian ini menggunakan kartu e-KTP sebagai kartu identitas warga Negara Indonesia yang fleksible untuk digunakan. Adapun gambaran sistem dapat dilihat pada gambar berikut:

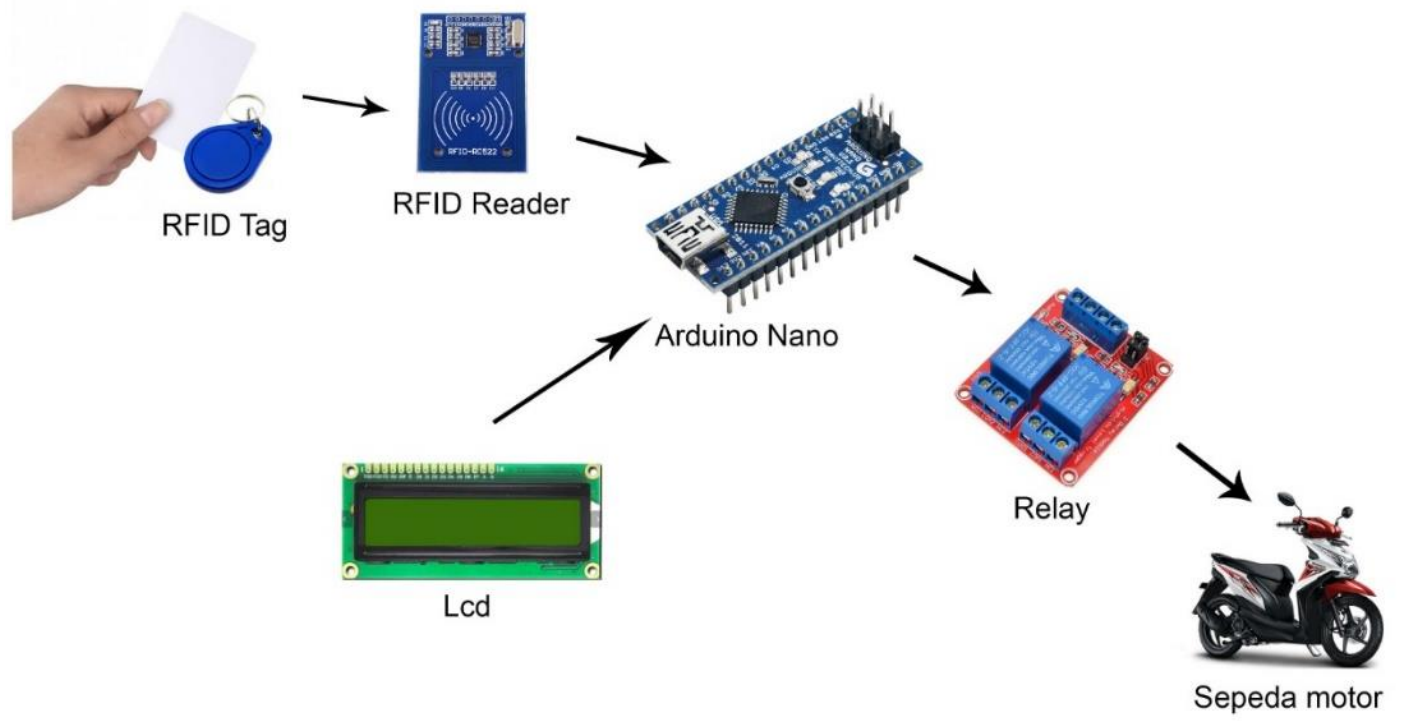

Gambar 2. Konsep Kerja Sistem

RFID taq yaitu e-KTP yang digunakan dalam penelitian ini digunakan sebagai kunci yang akan mengaktifkan sistem kelistrikan yang ada pada kendaraan bermotor. Kartu e-KTP yang ditempelkan pada sensor RFID akan dibaca id nya oleh sensor kemudian dikirimkan ke mikrokontroler untuk di proses lebih lanjut. Id RFID taq yang berisi kode unik tersebut diproses oleh sistem mikrokontroler untuk kemudian diperintahkan aktuator yaitu relay untuk mengaktifkan kelistrikan. Untuk konsep kerja sistem yang lebih jelasnya akan ditampilkan pada gambar berikut: 


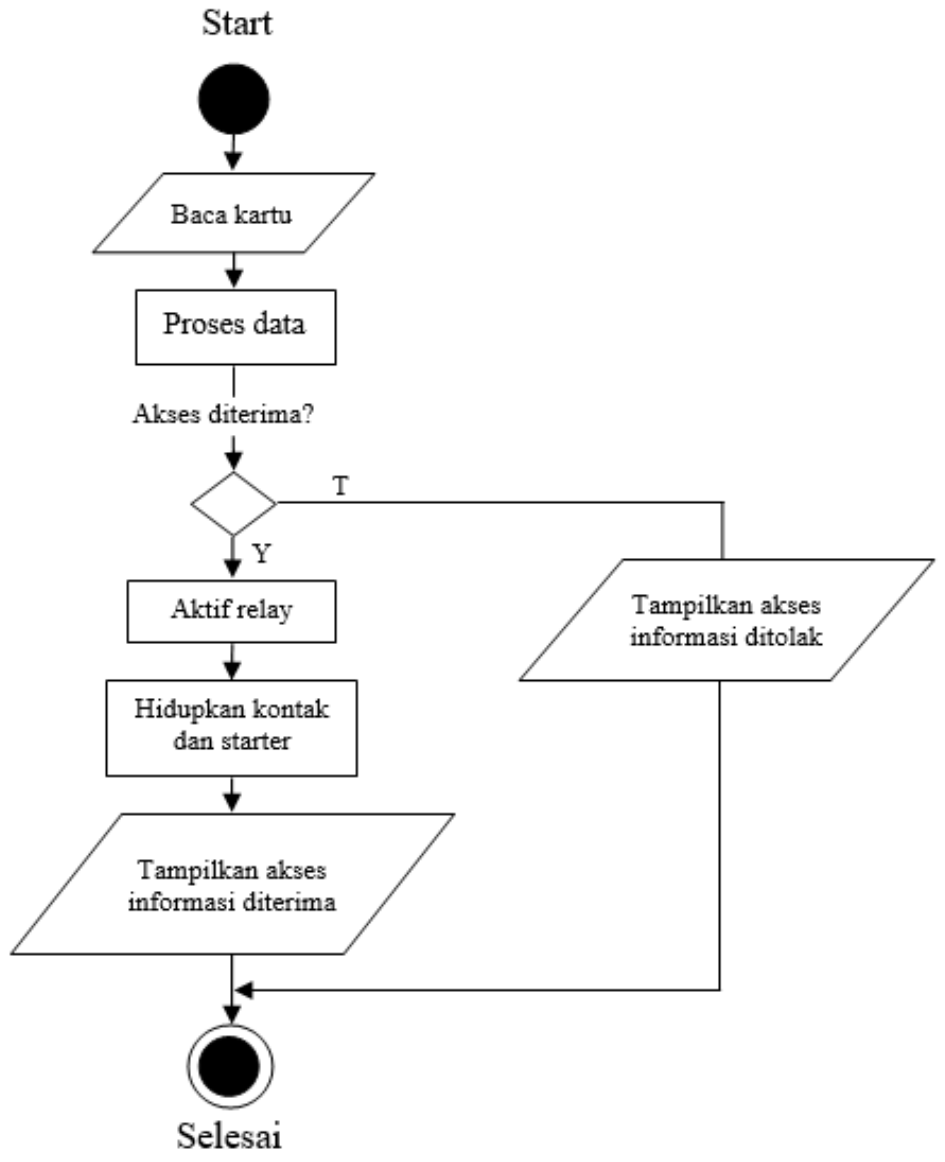

Gambar 3. Flowchart Konsep Kerja Sistem

C. Kebutuhan Perangkat Keras

Adapun kebutuhan perangkat keras dalam sistem penguncian kendaraan bermotor menggunakan RFID sistem dapat dilihat pada tabel berikut ini:

Tabel 1. Kebutuhan Perangkat Keras

\begin{tabular}{cclc}
\hline No. & Jenis & \multicolumn{1}{c}{ Fungsi } & Jumlah \\
\hline 1 & Arduino nano & Sebagai sistem pengolah input dan output & 1 \\
\hline 2 & RFID RC522 & Sebagai alat indentifikasi & 1 \\
\hline 3 & LCD & untuk menampilkan pembacaan RFID tag ID & 1 \\
\hline 4 & Power supply & Digunakan untuk mensuplai daya arduino nano & 1 \\
\hline 5 & RFID tag card & Sebagai input untuk di identifikasi & 1 \\
\hline 6 & $\begin{array}{c}\text { Modul relay 2 } \\
\text { channel }\end{array}$ & $\begin{array}{l}\text { Sebagai sklar untuk digunakan menghungkan dan } \\
\text { memutuskan kunci kontak dan starter }\end{array}$ & 1 \\
\hline 7 & Breadboard & Sebagai papan penghubung/koneksi rangkaian & 1 \\
\hline
\end{tabular}

\section{Hasil dan Pembahasan}

A. Implementasi Sistem

1. Master Card

Fitur master card diimplementasikan dengan tujuan agar sistem dapat dikontrol oleh single administrator dimana dengan menggunakan kartu master berarti super admin dapat menambahkan kartu e-KTP lainnya untuk dapat berfungsi sebagai kunci untuk menghidupkan kendaraan bermotor. Adapun gambaran nya dapat dilihat pada gambar berikut: 


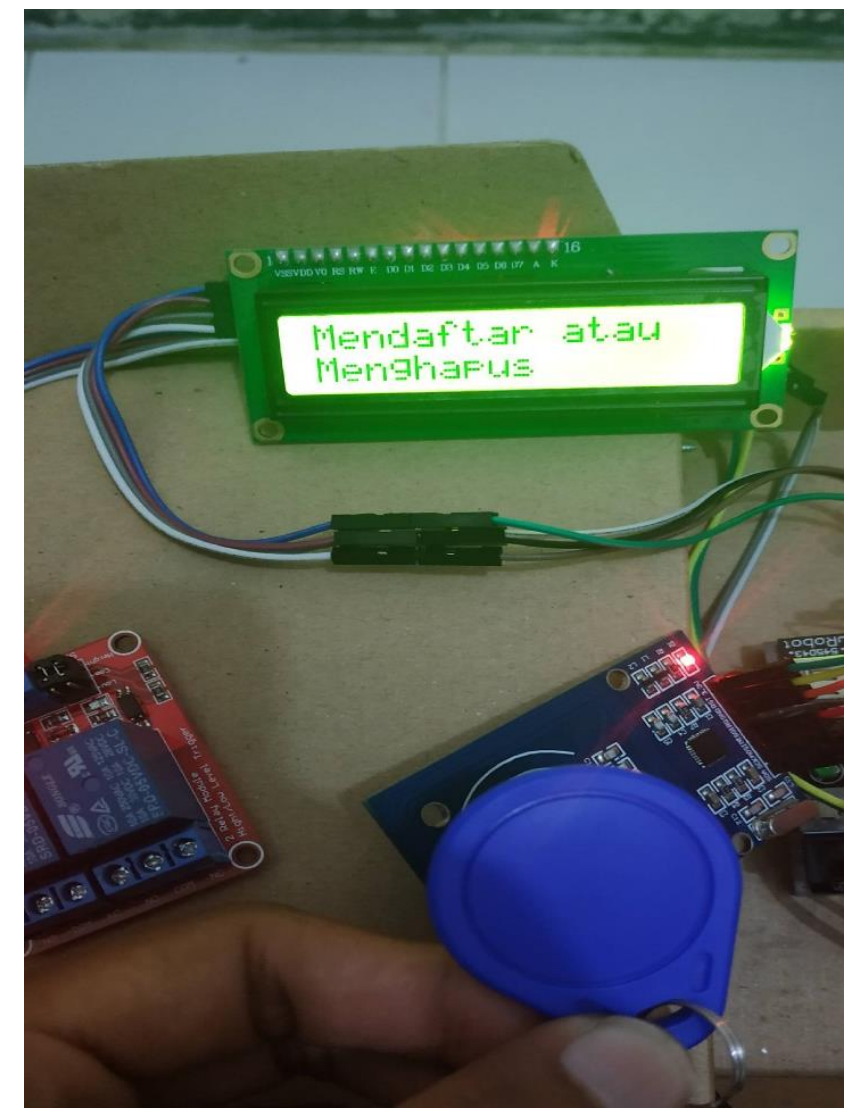

Gambar 4. Register and unregister key.

Kartu yang berhasil terdaftar akan diberitahukan oleh sistem. Begitu juga sebaliknya apabila proses register kunci baru mengalami kegagalan maka sistem juga akan memberitahu kepada user.

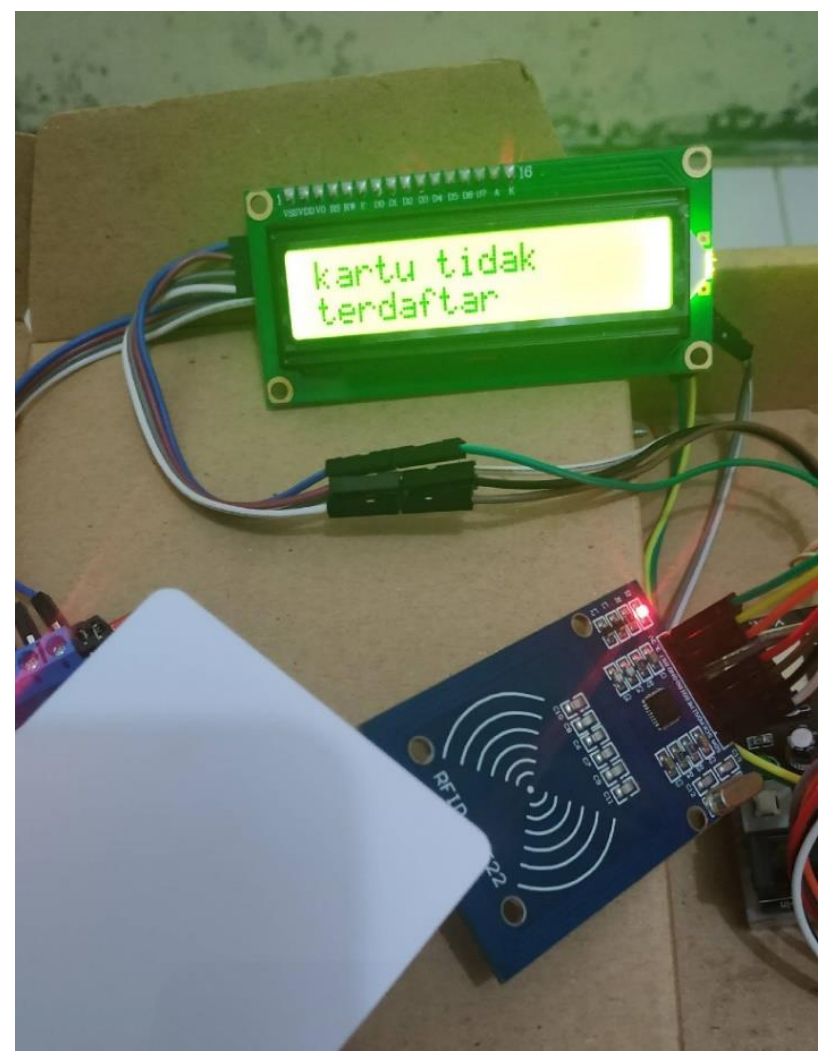

Gambar 5. Notifikasi sistem 
B. Hasil Implementasi keseluruhan

Hasil daripada implementasi sistem dapat dilihat pada gambar berikut ini:

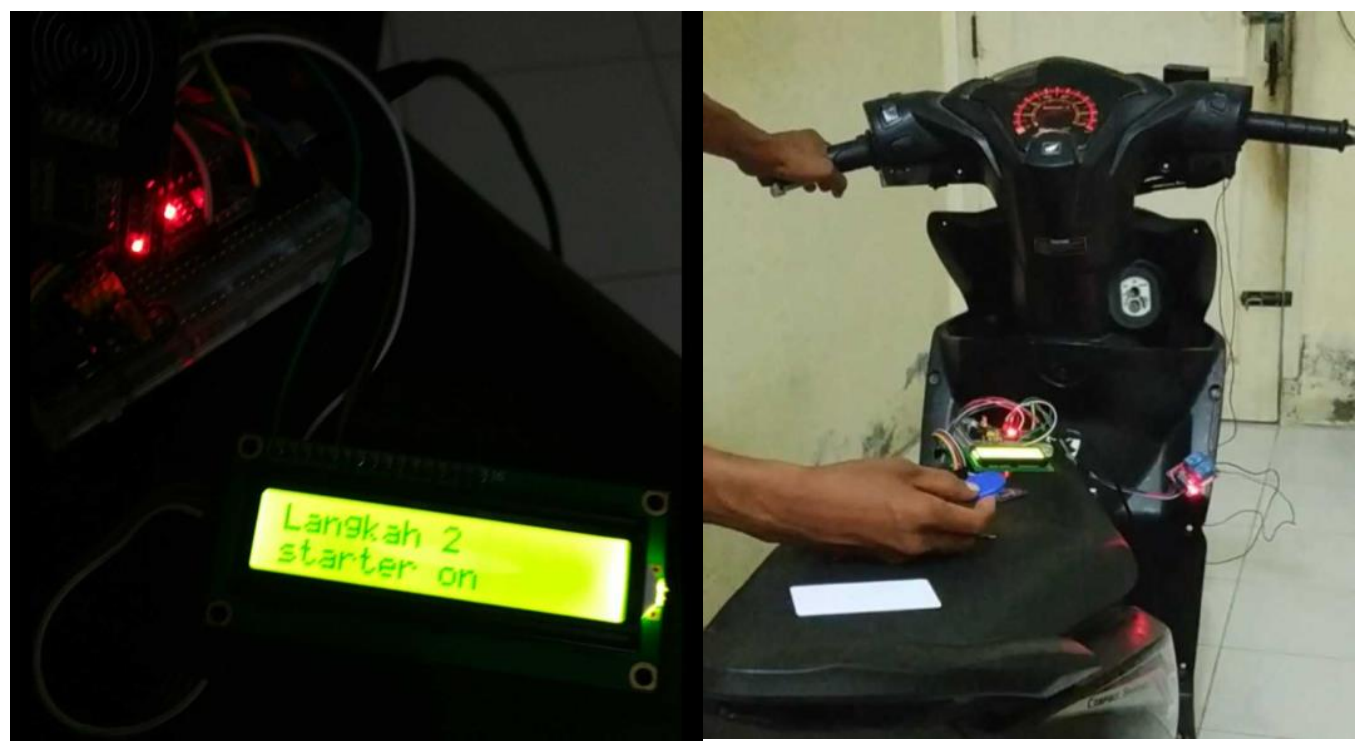

Gambar 6. Sistem Keseluruhan

C. Pengujian

1. Pengujian Jarak RFID

Konsep RFID yang menggunakan passive taq RFID seperti dalam penelitian ini tentu memiliki keterbatasn jarak kontak antara RFID Reader dan RFID taq. Hasil pengujian yang dilakukan menunjukkan hasil sebagai berikut:

Tabel 2. Hasil Pengujian Jarak RFID

\begin{tabular}{|c|c|c|}
\hline No. Pengujian & Jarak $(\mathbf{C M})$ & Keterangan \\
\hline 1 & $1 \mathrm{CM}$ & Terdeteksi \\
\hline 2 & $2 \mathrm{CM}$ & Terdeteksi \\
\hline 3 & $3 \mathrm{CM}$ & Terdeteksi \\
\hline 4 & $4 \mathrm{CM}$ & Tidak Terdeteksi \\
\hline 5 & $5 \mathrm{CM}$ & Tidak Terdeteksi \\
\hline 6 & $6 \mathrm{CM}$ & Tidak Terdeteksi \\
\hline 7 & $7 \mathrm{CM}$ & Tidak Terdeteksi \\
\hline 8 & $8 \mathrm{CM}$ & Tidak Terdeteksi \\
\hline 9 & $9 \mathrm{CM}$ & Tidak Terdeteksi \\
\hline 10 & $10 \mathrm{CM}$ & Tidak Terdeteksi \\
\hline
\end{tabular}

2. Pengujian dengan Material Penghalang

Dalam penelitian ini juga dilakukan pengujian untuk pembacaan RFID yang terlang dengan material tertentu. Adapun hasilnya dapat dilihat pada tabel berikut: 
Tabel 3. Pengujian dengan Material Penghalang

\begin{tabular}{|c|c|c|}
\hline \multirow[b]{2}{*}{ Tipe Material } & \multicolumn{2}{|c|}{ Kemampuan } \\
\hline & $\begin{array}{c}\text { Dapat } \\
\text { ditembus }\end{array}$ & $\begin{array}{c}\text { Tidak } \\
\text { tertembus }\end{array}$ \\
\hline Kertas 1 lembar & $\mathrm{Ya}$ & \\
\hline Kertas $>50$ lembar & $\mathrm{Ya}$ & \\
\hline Kertas $>150$ lembar & & Tidak \\
\hline Plastik & $\mathrm{Ya}$ & \\
\hline $\begin{array}{c}\text { Akrilik setebal } \\
0,5 \mathrm{~cm}\end{array}$ & $\mathrm{Ya}$ & \\
\hline Kain 1 helai & $\mathrm{Ya}$ & \\
\hline Kain setebal $5 \mathrm{~cm}$ & & Tidak \\
\hline Seng & & Tidak \\
\hline Besi & & Tidak \\
\hline Aluminium & & Tidak \\
\hline
\end{tabular}

\section{Kesimpulan}

Setelah melalui beberapa tahap dalam penelitian yang meliputi, perancangan, pembuatan, dan pengujian, makan dapat diambil kesimpulan sebagai berikut:

1. Pengaman kendaraan bermotor ini diharapkan mengurangi tindak kejahatan, karena pada sistem ini secara otomatis memiliki kunci ganda yang dapat dihidupkan dengan sistem RFID.

2. Dengan sistem ini pengguna masih menggunakan kunci fisik, namun hanya untuk melakukan penguncian stang kendaraan bermotor. Sedangkan untuk mengaktifkan fungsi kelistrikan dan untuk menghidupkan kendaraan bermotor sudah menggunakan alat keamanan tambahan RFID dengan e-KTP sebagai kuncinya.

3. Perangkat yang digunakan RFID RC522 sebagai penginput data. Modul ini bekerja $13,56 \mathrm{MHz}$ sebagai hak akses masuk dapat berjalan dengan optimal dalam batas jarak RFID tag maksimal $3 \mathrm{~cm}$

4. Untuk pembacaan RFID taq dengan jarak 1 meter perlu digunakan RFID reader yang bekerja pada frekuensi $125 \mathrm{KHz}$.

\section{Daftar Pustaka}

Artika, K. D. (2013). Rancang Bangun Sistem Pengaman Pada Sepeda Motor DenganMemanfaatkan Sensor Encoder Dan Sensor Ping. Jurnal ROTOR (Online), 6(1).

Asmawati, S., \& Sari, D. M. (2019). Penggunaan Perintah Suara Sebagai Sistem Kontrol Pengganti Kunci Kendaraan Bermotor Roda Dua. J-HEST Journal of Health, Education, Economics, Science, and Technology, 1(2), 81-86.

Astono, R. (2006). Implementasi Dan Perancangan Kunci Pintu Hotel Dengan Radio Frequency Identification (RFID). Universitas Negeri Semarang.

Chen, F.-J., Reade, W. C., \& Lindsay, J. D. (2005). RFID system and method for ensuring personnel safety: Google Patents.

Grabau, R. E., Mitchell, N. G., Nash, T. P., Palmer, E. V., Shipston, A. C., \& Soltysiak, J. R. (2002). RFID manufacturing concepts: Google Patents.

Iwan, I., Rahayu, H. E., \& Yulianto, A. (2018). Analisa Peramalan Permintaan Mobil Mitsubishi Xpander dengan Tiga Metode Forecasting. Jurnal Humaniora Bina Sarana Informatika, 18(2), 249-256.

Priyadi, B. (2017). Aplikasi Sensor Infrared Digunakan Sebagai Kunci Lemari Elektronik Menggunakan Kartu Berlubang Berbasis Mikrokontroller. JURNAL ELTEK, 11(1), 194-207.

Purnomo, D. (2017). Model Prototyping Pada Pengembangan Sistem Informasi. JIMP-Jurnal Informatika Merdeka Pasuruan, 2(2).

Risyad, L. M. (2018). Analisis inovasi produk Mitsubishi Xpander.

Youssef, B., Bassim, B. S., \& Gabriel, R. O. J. (2011). projet RFID. TELECOM Sud paris, Sud Paris. 